\title{
Practitioner Researchers in Vocational Education and Training
}

Rick Holden \& Erica Smith

\begin{abstract}
The research examined the issues facing vocational education and training (VET) practitioners who aspire to undertake formal research and move towards publishing their research. Research participants were drawn from attendees at a publishing workshop that was mounted at the 2008 conference of the Australian Vocational Education and Training Research Association (AVETRA). The research utilised notes made by the conveners of that workshop, and the collective work produced in groups of participants, responses to an email interview six months after the date of the workshop, and subsequent in-depth telephone conversations with three of the participants. The study showed that practitioner researchers faced considerable difficulties in pursuing their research and publication goals, and analysis of findings suggest that these difficulties may reflect a lack of 'place' for research within VET practice and VET institutions.
\end{abstract}




\section{Introduction}

In the vocational education and training (VET) discipline, as in others, there is an impetus and encouragement for practitioners to undertake research into policy and practice in the sector. In addition to the felt importance of practitioners undertaking research, there is also a concern in Australia about the sustainability of the body of VET researchers. This also leads to a perceived need to develop researchers within the sector itself. However, as practitioner researchers move beyond evaluation studies and small-scale research that affects their immediate area of work to more scholarly research that warrants peerreviewed publication, they encounter barriers and challenges that they may not have expected. This project set out to explore these barriers and challenges using the experiences of VET practitioners who had expressed an interest in publication.

\section{Background and Literature Overview}

The notion of practitioners researching and publishing is common in the education field. Many university courses for school-teachers, for example, include subjects on 'teacher as researcher'. Research by teachers is generally advocated as helping to improve their practice and is often linked to the research method known as action research, a form of involvement of researchers with groups of practitioners to improve practice, first propounded by Kurt Lewin in the 1940s. Teacher research is often referred to in the education literature as a form of professional development (Zeichner 2003, p.302), although it is also the case that teacher research produces new knowledge (eg Cochran- 
Smith \& Lytel 1999). While much literature on teacher research is uncritical and descriptive, it is also acknowledged that it is necessary to critique teacher research and recognise its drawbacks (Zeichner 2003, p.318).

In Australia, the National Centre for Vocational Education Research (NCVER), a major VET research organisation that also administers nationally competitive VET research grants, is an enthusiastic promoter of practitioner research. A review of NCVER was undertaken by the then Department of Education, Science and Training (DEST 2006), the government department that funds NCVER. While DEST did not take a position on the issue, it noted that during the national consultations with many stakeholders in VET research, some participants expressed concern about the ‘domination’ of university researchers in research into VET. DEST concluded that the system should be 'open at the margin to involvement of researchers who are new to the sector' (DEST 2006, p.12), although did not go so far as to state that these should be practitioner researchers. The report noted that of 418 grant applications received by NCVER for the five years 20012005 for its major competitive grant scheme, 211 were from universities and only 56 from TAFE Institutes. (TAFE is the public provider of VET in Australia) University researchers had a success rate of 50\% (81) while TAFE Institutes succeeded in only 7 applications (13\%) (DEST 2006, p.56). Private consultants had a higher success rate at 28 out of $121(29 \%)$.

The low success rate of VET-sector applicants for NCVER grants, a major source of Australian VET research funding, clearly indicates the need for capacity building within 
the sector if it is to become a major player in VET research. While uncompetitive grant applications do not necessarily mean a lack of capacity for research and publication, they do indicate some shortcomings. The DEST review therefore recommended, for example, the provision of mentoring opportunities within funded projects and an innovation fund to encourage new researchers. The review favourably mentioned the annual NCVER 'No Frills' conference, noting that it was aimed at practitioners; it was free of charge and that most of the presenters were practitioners who have not been in receipt of research funding (DEST 2006, p.12).

It is possible of course for VET-sector personnel to be engaged in research projects without initiating or leading them. It was noted by Smith (2004) that large research teams were becoming more common in NCVER-funded competitive grants and that these frequently involved practitioners. Individual partnerships between academics and practitioners are also present (Brown \& Hodges 2003), often in the context of the practitioners undertaking postgraduate studies. Involvement of practitioners in large research projects was also mentioned in the DEST review of NCVER (2006, p.31) who maintained that this involvement was 'a means of bringing practical expertise to the research projects'. However it may be that such research partnerships may not always be successful. It was noted during a major UK research program in VET teaching and learning, for example, that several of the designated practitioner researchers experienced adverse outcomes in relation to their standing and employment status within their own institutions (Hodkinson pers. comm., 2005). 
Practitioner research is not, of course, confined to the education discipline. It is a notion with much currency in nursing, for example, and in this discipline also it is recognised that it is not unproblematic in nature. Mitchell \& Jones (2004), for example, refer to the challenges of managing a research project carried out by a team of nurse practitioner researchers, and Priest, Segrott, Green \& Rout (2007) discuss a project which teamed academics with nurses in a major research study.

It is noteworthy that despite a seeming consensus that it is desirable for research to be carried out by people working within the VET sector in Australia, VET sector institutions are not funded for research, and many national sources of research funding (eg the Australian Research Council) do not allow grants to be given to people outside the university sector or not in designated research institutions. While there are a small number of research units within TAFE Institutes, it would be generally agreed that they have struggled for recognition and for funding. The base qualification for VET practice, the Certificate IV in Training and Assessment, does not include a unit of competency on research, although university level VET teacher training qualifications may contain at least an elective research unit.

\section{Research Method}

The authors of this paper are, respectively, Editor and Associate Editor of a major UKbased journal publishing in the VET area. At the 2008 conference of the Australian VET Research Association (AVETRA), the main professional body for those engaged in or 
interested in VET research, the authors offered a workshop for people wishing to learn more about successful publication in journals. AVETRA is an organisation whose membership is divided fairly equally between VET academics and VET practitioners, with some independent researchers and government officers (Miller 2008). Although the workshop was not targeted specifically to practitioners who wished to publish, in fact, 14 of the 17 participants (14 women, 3 men) were VET practitioners from TAFE Institutes (public providers of VET), private Registered Training Organisations (RTOs) including one secondary school that was an RTO, government departments and Skills Councils. During the workshop the following areas were covered:

- Information about published articles and peer review processes for the journal in question

- Working in groups, perceived barriers in getting published

- Editors' viewpoint on what gets published

- How to write an introduction that gets attention

- Reasons for rejection of articles

- Working with reviewers' comments

- Working in groups, producing a paragraph that could form the basis of an article from completed research

After the workshop it was decided to undertake some research with the participants on a longitudinal basis and they were contacted to seek their permission to utilise notes taken at the workshop by the presenter and produced in group work by the participants, and to be contacted six months after the workshop to see how their publishing plans were 
proceeding. Ethics approval was gained for the project. Six participants agreed to a follow-up email interview, five female and one male. Table 1 shows the organisations for which they worked.

Table 1: Respondents to the email interview and the nature of the organisations for which they worked

\begin{tabular}{lc}
\hline \multicolumn{1}{c}{ Type of organisation } & No \\
\hline Private RTO & 1 \\
TAFE & 2 \\
Fully retired & 1 \\
University & 1 \\
Australian Government & 1 \\
\hline
\end{tabular}

The email questionnaire contained six questions which were the following:

- Please briefly state what you remember learning from attending the publication workshop in April 2008.

- Was there anything that you would like to have seen covered, that was not?

- Thinking back to April 2008, describe your research and/or publication activity to that date, and your future plans at that time?

- Since April 2008 how have your research and publication plans progressed (if at all)?

- What events, experiences or people have benefited your development as a researcher and publisher?

- What issues have presented challenges or barriers to your development as a researcher and publisher? 
Of those undertaking the email interview, three agreed to a follow-up in-depth phone interview. Two of these participants worked for TAFE and one for a private RTO. The phone interviews were undertaken in December 2008, eight months after the initial workshop. They lasted for between 25-35 minutes and were recorded, with permission. The questions for this interview were as follows:

- Tell us a little more about what you do (your job) in the context of VET (and what you were doing in April if different). What was your previous career?

- How would you describe the research element of your job, if any?

- Do you feel you have progressed your interest or aspiration in researching and publishing since the workshop you attended (April 2008)? (and how?)

- If yes, what ONE factor would you identify as critical in enabling this progression? (and tell us about it)

- Thinking about this one factor and any others that have enabled your progression over time, how can these facilitating factors be better provided for yourself and/or other would-be researchers?

- If no, what one factor would you identify as critical in impeding this progression? (and tell us about it)

- Thinking about this factor and any others that have impeded your progression over time, how can these challenges or barriers be met or overcome for yourself and/or other would-be researchers?

- Other people have identified lack of time, including family and work responsibilities and an unsupportive work environment, as issues that have hindered their research and publication progression. Would you have suggestions 
for them about how to address these issues and challenges? What arguments could be made to an unsupportive manager to allow time or other resources for research?

- What organisations do you currently have contact with that relate to VET research and in what ways do you interact with them? In what ways have they assisted you in your development as a researcher and/or publisher?

While the focus of the initial workshop was on publishing, the subsequent research processes include questions about research more broadly. It may be regarded as a limitation of the research method that the focus shifted slightly during the project, and that the participants were originally self-selected as being interested in publication rather than precisely in research.

\section{Findings}

In this section the findings from each phase of the research are reported separately. They are then drawn together in the 'Discussion and Conclusion' section.

\section{Workshop notes}

The presenters' notes indicated that some participants found it a 'big leap' to move from 'finding things out' to 'putting a tag of research on it'. There were some concerns arising from lack of self-efficacy in publishing but others that related to worrying about exposing 
themselves or their organisations as a result of putting issues and data in print: 'it puts it in the public domain'. There were a few comments indicating dissatisfaction with academic conventions - one participant described them as ‘irritating' and one participant was nervous about being seen as 'wanting to get your name in print'.

The practitioners worked in groups to write down perceived barriers to publishing. The responses could be gathered into five main clusters of responses, which are listed below together with examples from each cluster.

Table 2: Clusters of barriers to publishing Type of barrier to publishing Examples of comments (as written)

Lack of self-confidence

Insufficient knowledge of VET sector

Lack of research skills

Lack of knowledge of research \& publishing conventions
- Worry ‘not good enough’ (i.e. quality of research

- Fear of rejection

- Not being a content specialist

- New to discipline area- so not strong on background issues

- Lack of background knowledge of topic

- Feeling like I don't know enough/everything.

- Lack of research expertise

- Ensuring analysis of research is good

- Interpreting data intelligently, knowing what is significant.

- Access to people to enhance initial research

- How much is enough for a literature review?

- Who do I send it to?

- I have had 2 papers reviewed and feedback from 2 reviewers have been poles apart. Neither gave the same or even similar comment. Who is right?'

- Appropriate language 
Lack of writing skills

- $\quad$ Keeping within a limited word count.

- $\quad$ Spelling; avoiding jargon (audience); writing competently, clearly and interestingly.

It is not perhaps unexpected that VET practitioners who were beginning to publish mentioned a lack of research skills, of self-confidence and of knowledge of research and publishing conventions. These remarks might be typical also of neophyte academic researchers. It was more of a surprise to see that some people felt they had insufficient VET knowledge and insufficient access to participants. It is perhaps too readily assumed that practitioners have good knowledge of the sector and a ready research 'base'. In fact their knowledge may be limited to their own area of operation and they may feel unconfident outside that specific area.

\section{Email survey}

The participants were first asked what they remembered about the workshop and what additional material they would have liked to have seen covered. Only three remembered anything in particular about the workshop. Among the items that they recalled were

- $\quad$ the message that one should not be deterred by lack of self-confidence;

- the importance of targeting appropriate journals;

- the need to structure publications carefully and writing concisely; and

- the need to be willing to make changes to written work as a result of review. 
Among suggested changes was the provision of more direct information about how to structure a paper, information about the differences in standards for different levels of publications (eg conference paper versus journal article) and more feedback on how to deal with feedback on written work

Participants were then asked to detail what their research and publication activity was at the time of the workshop, and what it was at the time of response to the survey, six months later. Two had been engaged in finishing their doctorates and one had been finishing a ‘New Researcher’ Paper for NCVER, which she described as ‘writing, editing, rewriting, editing, editing, editing.'

Two participants' responses are selected for Table 3 as showing significant advances in the six months since the workshop. It should be noted, however, that one of the respondents was one of the few university participants in the original workshop.

Table 3: Two participants' research and publication progress in six months

\section{Activity in April 2008}

- $\quad$ At that time I was unsure how to proceed and had let the idea drop. (participant 4)

- While my goals were unclear at the time, I was keen to write high quality publications. Being new to the university sector, I knew I needed support. (participant 5)

\section{Activity in October 2008}

- Yes, significantly. I have teamed up with a colleague, we developed our action plan and we have ethics approval from our Institute and are developing the initial survey tools. We plan to carry out the research and present next year (possibly AVETRA if we get finished in time)

- A paper presented at the VOCED conference and another submitted for peer review at the EDUCAUSE Australasia conference; this conference didn't accept a VET-based paper but I had one accepted on another topic. I have also submitted an application to enrol in a PhD. 
When asked what experiences benefited their development as researchers and publishers, the six participants had several to report. They included:

- Networking with experienced people and with other new researchers;

- A demonstrated need and demand for the findings of their research from their own organisations and/or practitioners in other organisations;

- Attendance at conferences;

- Discussion with research supervisor (this participant was undertaking a $\mathrm{PhD}$ );

- Writing with other researchers;

- Helping other researchers; and

- The status of being a published researcher.

The largest barrier to research (mentioned by four of the six participants) was time. One participant mentioned a move to another job, away from VET.

$\underline{\text { In-depth telephone interviews }}$

Table 4 provides information about the three participants who agreed to undertake telephone interviews. Pseudonyms are utilised and have been selected to disguise gender.

Table 4: Telephone interviewees

\begin{tabular}{llll}
\hline $\begin{array}{l}\text { Name } \\
\text { (pseudonym) }\end{array}$ & Age & $\begin{array}{l}\text { Employing } \\
\text { organisation }\end{array}$ & Brief biography \\
\hline Lindsay & 45 & TAFE & $\begin{array}{l}\text { Acting manager for a teaching department; } \\
\text { previous role as senior educator/program co- } \\
\end{array}$ \\
& & $\begin{array}{l}\text { coordinator and in industry in graphic arts; } \\
\text { currently enrolled in part-time PhD. }\end{array}$
\end{tabular}


Chris $\quad 50 \quad$ TAFE $\quad$ Professional development role; previous work in accredited staff development programs; about to start part-time research masters.

Alex $40 \quad$ Private RTO Quality manager for RTO; previous work with another RTO and with TAFE; previous careers in industry in marketing and advertising. Participant in NCVER program for new researchers; has completed a masters by research; wants to enrol in a $\mathrm{PhD}$ soon.

Research orientation: Each of the three participants had a personal orientation towards research. Although none had research as a designated part of their job, each was undertaking or had recently undertaken personal study in VET or adult education. Proceeding directly from one qualification into another seemed to be a useful strategy, as the practitioners were in the swing of study and accustomed to giving up personal time: as Chris put it 'suspending one’s private life'. Through this study they had become familiar with searching for relevant literature, both through formal databases such as NCVER’s 'VOCED’ database, or journal databases, and through Google Scholar. Although not undertaking formal research at work they each said that they used research methods to find out more for work-related tasks such as writing funding proposals, researching business opportunities or mounting an argument to senior management about an issue. They understood the importance of having evidence with which to argue. The two TAFE participants were provided with VET research papers from their senior managers along with other TAFE staff, through the internal intranet.

Factors that assist in research activities: Enthusiasm for the area of research appeared to motivate the participants. They had all chosen a research topic that personally excited 
them and that, in all cases, was relevant to their work. All participants also referred to groups or individuals that supported people. In the case of the TAFE participants, both mentioned other people undertaking research higher degrees and minor theses. Such people served as role models and then provided mutual support. Progressing past the masters stage diminished the size of the local group and therefore the available support. In the case of Alex, a fellow participant in the program for new researchers, although at a distance, provided regular telephone support:

"We just get on the phone and have a whinge and motivate and a glass of wine and talk about what we've done and set goals and write a bit and send it to each other, even if it looks rubbish.”

Attendance at conferences and other research events was a great motivator. Lindsay reported on the conference at which the realisation came that the standard was not unachievable.

"I enjoyed sort of the papers that people presented and that I thought gee look...I didn’t feel like there was...I mean there were some very, very sophisticated things presented but at the time I felt that some of the stuff I was writing would stand up.”

The next target was to publish in a journal: 
“To actually have something in a journal I think would be grouse. I'd love to be a proper published writer. That's what I'll be aiming for.”

Alex reported on the extra motivation associated with conferences when a group of people decided to attend:

“Three of us decided to do some research and we've all put in abstracts for AVETRA next year and we all got accepted which we're thrilled about. Two of us are working with other people as well, so, yeah, we’ve very much got a bit of a consortium going and we’ve also started a reading group here.”

Chris mentioned the presence of a statistics expert at the TAFE Institute, who was available to assist with research projects. Chris was using this expert to assist with statistical analysis; quantitative methods were being used to combat a self- perceived lack of objectivity in qualitative methods in an area about which this practitioner felt passionately.

Time management: All of the participants had demanding full-time jobs and in Alex's case casual work on top of that. Two had small children and one was a single parent. They had all worked out strategies for carving out research time. Chris was too tired to undertake research study in the evening and so took most of the weekend on this task, in between family commitments; Alex had sufficient energy in the evenings; Lindsay tried to find time during the working week because of exhaustion in the evenings. 
How to 'sell' research activities to senior managers: Finding time to do research as a practitioner meant having to justify the activity to managers. All participants mentioned the need to impress upon senior managers the importance of good research for the organisation's long-term reputation and to underpin short-term initiatives. As Lindsay said,

“The ability to research and get some information and then to disseminate it and then to shape it into something new is a real powerful tool, for first of all changing the way I work, and benefiting the students and those kinds of things.”

The two TAFE participants said that in theory the importance of research was accepted by managers and there was 'lots of moral support' but this did not always translate into available time. There were some suggestions abut how other practitioner researchers could manage to 'win' time for research: Lindsay suggested using the professional development time that was part of the TAFE teacher industrial agreement, and Alex suggested that when embarking on a research project which managers supported in a general way, a document should be agreed by both parties that specified the amount of release time. Having agreement to undertake a research degree generally meant that managers were prepared to allow time during the working day, at least on occasion. Lindsay also suggested that talking about the research content area with senior managers helped to win their support. More generally all were clear that their developing research skills were useful for their organisations; as Chris put it, 
"When you delve and when you research things it just helps your understanding of so many things."

Lindsay referred to 'developing another set of eyes to be more objective about things'; research had helped this practitioner understand that there were always several ways of looking at a workplace issue.

The most significant message from talking to these three dedicated researchers was that the existence of an external framework for researching was of importance. Being enrolled in a research higher degree, as Lindsay and Chris were (or were about to be), or undertaking a funded project, albeit minor, as Alex was, provided external motivators, deadlines and benchmarks. The presence of support from peer groups and/or in the workplace was important too, but without the external framework it is easy to imagine that planned projects might fall by the wayside of regular pressing work activities.

\section{Discussion and Conclusions}

The Discussion part of this paper seeks to achieve two goals. First, to draw an interpretation of the evidence as presented by those participants to this research. Second, to speculate on what might be a more significant and at the same time more concerning ‘constraint’ affecting aspirant research writers amongst VET practitioners. 
There is little in the data to suggest that provision of the sort of workshop discussed in this paper offers a smooth pathway from aspirant to successful publication. As Jutel (2008) notes, addressing the issue of academics in a newer university in new Zealand, whilst technical expertise and awareness of the machinations of the writing for publication system are clearly a necessary part of the successful writer's toolkit they only materially affect outcomes if other, more contextual factors, combine together to provide the right mix of conditions to support writing for publication.

The context for the VET practitioners in the current study is the lack of a clear external 'driver' within the world of VET. This makes the task of the would be researcher and writer very difficult. The seeming consensus of the value of research undertaken by VET practitioners and its links to reflective practice and continuous professional development do not translate into a clear positioning of research and published research as an integral aspect of assessment of VET practitioners' performance. Given such a state of affairs it is unsurprising that there is little recognisable, formal support system within the VET workplace to assist individuals turn an interest into an outcome.

The latter phase of the research discussed here focused upon those who had made some progress down a pathway of research and writing for publication, possibly because only those who were comfortable with their progress may have volunteered to see the research study through to its conclusion. The picture presented is of individuals succeeding 'against the odds'. It illustrates individuals with sufficient personal drive to overcome a 
set of constraints and thus for whom the technical appreciation of how best to target a journal, write an abstract and so on, becomes a meaningful capability. In all three cases these activities were supported by a structure outside work, which in two cases was provided by engagement in a research higher degree at a university.

The constraints on those trying to research within their work environment seem to be a complex mix of social / personal (motivation, identity, existing level of professional knowledge etc ) and organisational factors (management attitudes, support, communities of practice, the positioning of research within work etc). Three points, which we consider to be of particular importance in understanding pathways to address or work through the constraints are developed here. Critically the first two are inextricably inter-related.

Support for translating research into published outcomes is likely to come from a variety of sources. Manning and Hogg (2006) note 'the skills of writing for research can be learnt best from those who use them most.' More specifically, a research mentor that was more senior in the organisation, for example, would appears to offer a very effective support for the novice researcher. However, there is no specific mention of such a person by any of the participants in this study. This is perhaps only to be expected, as research and publication are not recognised roles within VET institutions, unlike in universities where senior academic managers are expected to have strong research and publication track records. Due perhaps to the lack of senior mentors/role models, peer support networks appear highly valued, either relatively intimately with a fellow 'aspirant' ('we just get on the phone and have a whinge'), through informal support groups for colleagues 
undertaking research degrees, or more vicariously through participation at a conference. Importantly though, these appear driven by self perception ('I knew I needed support') and a sense almost of 'comrades in adversity' ('we've got a bit of a consortium going'). But noticeably, there is little mention of support at and through work. It appeared that VET managers may have paid only lip service to support for research activity and research related activity. This is intricately related to our second point.

Some data from the first phase of the research suggested that a lack of knowledge of VET was felt by some to impinge upon the opportunity and capability to engage in successful research based writing. We might speculate, therefore, that engaging in VET practice may not always provide a sufficient sense of understanding of the issues facing the sector to support research activity and research based writing. Similarly, daily work is not, or only partly, engaging the employee in research related activity. In a similar point in a different occupation, a study of new library professionals Bradley (2008) found that while research and writing is viewed as favourable for librarians, few were actually required to write as a part of their work role. In other words, work matters. In universities, academics are required as part of their jobs to research and publish and hence these activities form a major part of the work culture. In the VET sector this culture, which provides both stresses and supports to academics, appear to be missing. Issues of lack of time, low self-efficacy and unfamiliarity with the publishing 'system', are familiar to all those who seek to research and publish. But in the case of VET practitioners these may be seen to mask a more structurally based constraint which is that VET practice rarely rewards research and publication and may not provide a good 
grounding in knowledge and skills that are required for this work. Yet as our participants mentioned, skills learned in research work prove useful in other areas VET practice.

The third point that emerged from the research was raised by participants at the original workshop although not taken up later, so this finding may not be very strong. In some cases it was felt that management in VET institutions would not approve of certain issues or findings being put into the public domain. This perception, assuming it is wellfounded, relates to the different nature of VET institutions from universities. In the latter, the concept of 'academic freedom' provides researchers with the right to publish anything provided it is based on evidence and subject to codes governing good practice in research, ethics conventions and so on. This right to publish would - and does - extend to the right to publish studies in the higher education discipline that include the findings of research done within one's own institution, without any expectation that the work would be 'vetted' either by management or by self-censorship.

Evidence from the UK suggests that those working in the 'new' universities and in the Further Education sector face more constraints in terms of research simply as result of the nature of their work (Tariq \& Cochrane, 2003; Henkel, 1997). In other words, in institutions operating with a dominant teaching paradigm ('mass' higher education) the nature of the work offers few incentives and integral support to follow a research/research publication pathway. Importantly, the prevailing identity is one of ‘teacher’ not 'researcher'. It is not unreasonable to consider that VET exhibits these characteristics albeit to an even greater extent. 
Of course the limited amount of data that this small study provides means that these lines of argument must remain somewhat speculative. The extent to which VET practitioners (in Australia) are facing such pressures clearly remain an issue for further research. Such research, it is suggested, is important because of the taken-for granted-assumptions that practitioner research is important and desirable in VET. These assumptions, if not supported by conducive environments for research, may lead to unwarranted stresses and strains upon those VET practitioners attempting to 'live the dream'.

\section{References}

Bradley, F 2008, 'Writing for the profession: the experience of new professionals', Library Management, vol 29, no.8/9.

Brown, M \& Hodges, D 2003, 'Thoughtful and strategic practitioner research in Australian VET', Journal of Vocational Education \& Training International Conference, London, July.

Cochran-Smith, M \& Lytle, S 1999, 'The Teacher Research Movement: A Decade Later', Educational Researcher, vol 28, no.7, pp.15-25.

Department of Education, Science \& Training (DEST) 2006, Review of the National Centre for Vocational Education Research Ltd Research \& Statistical Services, DEST, Canberra.

Henkel, M 1997, 'Academic values and the university as corporate enterprise', Higher Education Quarterly, vol 51, no.2.

Hodkinson, P 2005, Leading researcher, TLRP project, pers. comm., May.

Jutel, A 2008, 'Writing for publication in the Polytechnic or 'New University' Sector', Care, vol 1, no.2, pp.26-34.

Manning, D \& Hogg, P 2006, 'Writing for publication’, Radiography, vol 12, no.2, pp.77-78.

Miller, C 2008, A history of AVETRA 1997-2007, AVETRA, Sydney. 
Mitchell, T \& Jones, S 2004, 'Leading \& co-ordinating a multi-nurse researcher project', Nurse Researcher, vol 12, no.2, pp.42-55.

Priest, H, Segrott, J, Green, B \& Rout, A 2007, 'Nurse Education Today', vol 27, no.6, pp.577-587.

Smith, A 2004, 'Never mind the width, feel the quality: The quality and impact of VET research in Australia', Research in Post-Compulsory Education, vol 9, no.2, pp.203-216.

Tariq, V \& Cochrane, A 2003, 'Reflections on key skills: implementing change in a traditional university’, Journal of Education Policy, vol 18, no.5.

Zeichner, KM 2003, 'Teacher research as professional development for P-12 educators in the USA', Educational Action Research, vol 11, no.2, pp.301-325. 